\title{
Magnetic multiwalled carbon nanotubes as nanocarrier tags for sensitive determination of fetuin in saliva
}

\author{
Esther Sánchez-Tirado, Araceli González-Cortés, Paloma Yáñez-Sedeño*, José M. Pingarrón \\ Department of Analytical Chemistry, Faculty of Chemistry, University Complutense of Madrid, 28040 Madrid, Spain
}

\section{A R T I CLE INFO}

\section{Keywords:}

Fetuin

Electrochemical immunosensor

Magnetic carbon nanotubes

Saliva

\begin{abstract}
A B S T R A C T
This paper reports the development and performance of an electrochemical immunosensor using magnetic multiwalled carbon nanotubes ( $m$-MWCNTs) as nanocarrier tags for the determination of human fetuin A (HFA), a relevant biomarker of obesity, insulin resistance, and type-2 diabetes as well as for pancreatic and liver cancers and inflammatory processes. Screen-printed carbon electrodes were grafted with $p$-aminobezoic acid and streptavidin was covalently immobilized on the electrode surface. A biotinylated capture antibody was immobilized through streptavidin-biotin interaction and a sandwich assay configuration was implemented using $m$-MWCNTs conjugated with HRP and anti-HFA antibodies as the detection label. The determination of HFA was accomplished by measuring the current produced by the electrochemical reduction of benzoquinone at $-200 \mathrm{mV}$ upon addition of $\mathrm{H}_{2} \mathrm{O}_{2}$ as HRP substrate. The prepared $m$-MWCNTs were characterized by SEM, TEM, XRD and EDS. All the steps involved in the immunosensor preparation were monitored by electrochemical impedance spectroscopy and cyclic voltammetry. A linear calibration plot for HFA was found between 20 and $2000 \mathrm{pg} / \mathrm{mL}$ with a LOD value of $16 \mathrm{pg} / \mathrm{mL}$. This performance is notably better than that reported for an ELISA kit and a chronoimpedimetric immunosensor. The favorable contribution of $m$-MWCNTs in comparison with MWCNTs without incorporated magnetic particles to this excellent analytical performance is also highlighted. The immunosensor selectivity against other proteins and potentially interfering compounds was excellent. In addition, the usefulness of the immunosensor was demonstrated by the analysis of HFA in saliva with minimal sample treatment.
\end{abstract}

\section{Introduction}

Human Fetuin A (HFA), also known as $\alpha 2$-Heremans-Schmid glycoprotein (AHSG), is encoded by the AHSG gene on chromosome 3. Plasmatic HFA is a $59 \mathrm{kDa}$ disulfide bond-linked two chain polypeptide consisting of two N-terminal cystatin domains and a smaller C-terminal domain (Dziegielewska et al., 1990). HFA is considered as a candidate biomarker of obesity, insulin resistance, and type-2 diabetes. High HFA serum concentrations have been observed in individuals with fatty or swollen liver (Yilmaz et al., 2010) related with increased risk of type-2 diabetes (Dabrowska et al., 2015). The relevance of HFA as a new potential biomarker for pancreatic and liver cancers and in metastasis of tumor cells (Sakwe et al., 2010) (Yi et al., 2009) as well as to differentiate prostate cancer and benign prostatic hyperplasia (Silva et al., 2016) has been also claimed.

\footnotetext{
* Corresponding author.

Email address: yseo@quim.ucm.es (P. Yáñez-Sedeño)
}

In addition, the synthesis of HFA is down-regulated during injury and inflammation (Choi, 2016) and plays an important role in blood vessel calcification (Schinke et al., 1996). As HFA acts as a potent inhibitor of calcium-phosphate precipitation and the calcification process, its levels are also related with dental calculus which is the first response in the inflammation of tooth supportive tissues (Doğan et al., 2016). Therefore, the relationship between HFA and the periodontal disease makes the determination of HFA in saliva relevant.

Due to the clinical importance of HFA, assays using different bioreagents for HFA detection have emerged. Table S1 in the Supplementary material summarizes the characteristics of commercially available ELISA kits involving sandwich-type configurations, peroxidase-labeled immunoreagents and colorimetric detection through the TMB $/ \mathrm{H}_{2} \mathrm{O}_{2}$ system. For instance, the Quantikine Human Fetuin A Immunoassay (https: //www.rndsystems.com/products/human-fetuin-a-quantikine-elisa-kit_ dfta00) is a 4.5-h solid-phase colorimetric ELISA that provides a calibration plot in the $7.8-500 \mathrm{ng} / \mathrm{mL}$ range and a minimum de- 
tectable dose (MDD), defined as the concentration corresponding to the mean absorbance of zero standard replicates $(n=20)+2 \mathrm{~s}$, of $0.62 \mathrm{ng} /$ $\mathrm{mL}$.

In the case of electrochemical biosensors, the strong interaction of HFA glycoprotein with specific lectins has been explored (Table S1). Specifically, Bertok et al. (2013a, 2013b) developed an impedimetric biosensor involving the Sambucus nigra lectin and a mixed SAM of 11-mercaptoundecanoic acid and 6-mercaptohexanol. Biorecognition of fetuin was accomplished through carboxyl group activation and lectin adhesion. Electrochemical impedance spectroscopy (EIS) was used as transduction technique. The same authors developed a more sensitive biosensor where a linker layer of amino-terminated alkanethiol was assembled on a gold electrode for further incorporation of gold nanoparticles The limit of detection achieved was $0.5 \pm 0.1 \mathrm{aM}$ (Bertok et al., 2013a, 2013b).

Nagaraj et al. (2010) developed another lectin-based biosensor for the label-free detection of HFA. They used a silicon chip with a row of gold electrodes and relied on the impedance variations upon HFA binding to lectins. The limit of detection was $1 \mathrm{pg} / \mathrm{mL}$. Moreover, a label-free electrochemical biosensor using Cratyliamollis lectin (Cramoll 1,4), assembled carboxylated carbon nanotubes and poly-L-lysine film was also proposed using square-wave voltammetry. A limit of detection of $0.017 \mu \mathrm{g} / \mathrm{mL}$ was achieved (Silva et al., 2016) (Table S1).

It is well known that the advantageous analytical capabilities of electrochemical immunosensors become more evident when using nanomaterials which can increase the loading of electrochemically detectable species as well as catalyze the electrochemical reaction enhancing the electrochemical signal (Ding et al., 2013). Carbon nanomaterials can be utilized in different amplification routes in electrochemical biosensing which mainly imply their use as electrode materials, redox mediators or carriers for signaling elements (Yáñez-Sedeño et al., 2017). Very recently, a fullerene-PAMAM(G5) composite was used for the preparation of a chronoimpedimetric immunosensor for HFA showing a 5-400 ng/ $\mathrm{mL}$ linear range with a LOD of $1.44 \mathrm{ng} / \mathrm{mL}$ (Uygun et al., 2018).

Apart from this article, to our knowledge, there are no other configurations reported for electrochemical immunosensors for HFA. Here, we describe the development and performance of an electrochemical immunosensor using magnetic multiwalled carbon nanotubes ( $m$-MWCNTs) as nanocarrier tags for the determination of HFA in the $20-1000 \mathrm{pg} / \mathrm{mL}$ with a LOD of $16 \mathrm{pg} / \mathrm{mL}$. Screen-printed carbon electrodes were modified by grafting with $p$-aminobezoic acid and, upon activation of the surface-confined carboxylic groups, streptavidin was covalently immobilized and, after conjugation with biotin-anti-HFA capture antibody, a sandwich scheme was prepared using m-MWCNTs(-HRP)-anti-HFA conjugates as the detection label. The excellent biosensor performance allowed the determination of HFA in saliva at clinical levels.

\section{Experimental}

\subsection{Reagents and solutions}

The antibodies used and the HFA protein were those included in the DuoSet®ELISA Development System from R\&D Systems (DY1184). A goat biotinylated anti-HFA antibody was used as the capture antibody. Biotin-anti-HFA $36 \mu \mathrm{g} / \mathrm{mL}$ solutions in phosphate buffer of $\mathrm{pH} 7.4$ were also used. Detection antibody was a mouse anti-HFA dissolved in the same buffer solution. Aqueous streptavidin (Strept, Sigma) solutions were firstly prepared and diluted with $25 \mathrm{mM} 2-(\mathrm{N}$-morpholine)ethanesulfonic (MES) (Gerbu) of $\mathrm{pH}$ 5.0. Lithium perchlorate (Sigma), $p$-aminobenzoic acid ( $p$ ABA, Acros), and absolute ethanol (VWR Chemicals) were used for the grafting protocol. Covalent immobilization of capture antibody was carried out with 1-ethyl-3-(3-di- methylaminopropyl) carbodiimide (EDC) and sodium $N$-hydroxysulfosuccinimide (NHSS) (Acros). D-biotin (Gerbu) was used as the blocking agent. Solutions were prepared in phosphate buffer of $\mathrm{pH}$ 7.4.

Ascorbic acid (AA, Fluka), uric acid (UA, Sigma), bovine serum albumin (BSA, Gerbu), cortisol (CL), creatinine (CR), estradiol (E2) and human immunoglobulin G (IgG), all from Sigma, interleukin-1 beta (IL-1 $\beta$ ), transforming growth factor beta 1 (TGF- $\beta 1$ ), and tumor necrosis factor alpha (TNF- $\alpha$ ), all from R\&D Systems, interleukin-6 (IL-6) and interleukin-8 (IL-8) from Abcam, were checked as potential interferents. Hydrogen peroxide (Aldrich, 30\% (w/w)) and hydroquinone (HQ, Sigma) were also used.

Other buffer solutions used were: $0.01 \mathrm{M}$ phosphate buffer saline (PBS) of pH 7.4 prepared by dissolving $\mathrm{Na}_{2} \mathrm{HPO}_{4}$ (Scharlau) and $\mathrm{KH}_{2} \mathrm{PO}_{4}$ (Merck) in $137 \mathrm{mM} \mathrm{NaCl}$ (Labkem) and $2.7 \mathrm{mM} \mathrm{KCl}$ (Probus) aqueous solution. $0.1 \mathrm{M}$ and $0.01 \mathrm{M}$ PBS of $\mathrm{pH} 7.0$ prepared by dissolving $\mathrm{Na}_{2} \mathrm{HPO}_{4}$ and $\mathrm{NaH}_{2} \mathrm{PO}_{4}$ (Labkem) in $150 \mathrm{mM} \mathrm{NaCl}$ aqueous solution; $0.1 \mathrm{M}$ PBST of $\mathrm{pH} 7.0$ prepared by adding $5 \mu \mathrm{L}$ of Tween ${ }^{\circledR} 20-10 \mathrm{~mL}$ of $0.1 \mathrm{M}$ PBS of $\mathrm{pH} 7.0$, and $0.05 \mathrm{M}$ phosphate buffer (PB) of $\mathrm{pH} 6.0$ prepared by dissolving $2.180 \mathrm{~g}$ of $\mathrm{K}_{2} \mathrm{HPO}_{4}$ in distilled water and adjusting the $\mathrm{pH}$ value.

All reagents used were of analytical grade. Deionized water $\left(18.2 \mathrm{M} \Omega \mathrm{cm}\right.$ at $\left.25^{\circ} \mathrm{C}\right)$ was obtained from a Millipore Milli-Q purification system.

\subsection{Apparatus and electrodes}

Amperometric measurements were done with an INBEA Biosensores potentiostat equipped with the Ib-Graph software. Impedimetric and voltammetric measurements were performed with a $\mu$ Autolab type III potentiostat controlled by FRA2 and GPES 4.7 (EcoChemie) softwares, respectively. A Crison Basic $20+$ pHmeter, an ultrasonic bath Elmasonic S-60 (Elma), a Vortex (Velp Scientifica) stirrer, and a Dynal MPC-S 120.20 (Dynal BiotechASA) magnetic separator, were also used. Characterization by SEM, EDX, TEM and XRD were performed using a FESEM (Field Emission Scanning Electron Microscope): JEOL JSM 7600F, a TEM: JEOL JEM 1400, and a difractometer PAMalytical model X'Pert MPD.

Screen printed carbon electrodes (SPCEs, $110 \mathrm{DRP}, \phi 4 \mathrm{~mm}$ ) were from DropSens (Oviedo, Spain). These electrodes were provided with a carbon counter electrode and a silver pseudo-reference electrode.

\subsection{Procedures}

\subsubsection{Preparation of the modified SPCES}

The screen-printed carbon electrodes were modified by immersion in an ethanolic $p$-ABA solution containing $\mathrm{LiClO}_{4}$ and making three successive cyclic voltammograms between 0.0 and $0.6 \mathrm{~V}$ at $30 \mathrm{mV} / \mathrm{s}$. Then, the modified electrodes were washed with deionized water and let dry at air. The grafted surface carboxylic groups were activated by dropping $10 \mu \mathrm{L}$ of a $100 \mathrm{mM}$ each EDC/NHSS solution prepared in $25 \mathrm{mM}$ MES buffer of $\mathrm{pH} 5.0$, and allowing incubation for $30 \mathrm{~min}$. Once the electrodes were washed and dried again, modification with streptavidin was performed by casting $5 \mu \mathrm{L}$ of a $600 \mu \mathrm{g} / \mathrm{mL}$ Strept solution prepared in the same buffer solution and incubating for $60 \mathrm{~min}$.

\subsubsection{Preparation of magnetic MWCNTs}

$25 \mathrm{mg}$ of MWCNTs were dispersed in $85 \mathrm{~mL}$ of Milli-Q water by ultrasonic stirring for one hour. Then, $16 \mathrm{~mL}$ of concentrated nitric acid were added and refluxed for $24 \mathrm{~h}$. The resulting dispersion was centrifuged at $4000 \mathrm{rpm}$ for $10 \mathrm{~min}$ at room temperature. The carboxylated MWCNTs were washed with Milli-Q water up to washing water reached $\mathrm{pH} 7.0$ and let dry under nitrogen stream. Magnetization of 
the resulting HOOC-MWCNTs was performed by suspending $19.4 \mathrm{mg}$ in $10 \mathrm{~mL}$ of water, adding $13.1 \mathrm{mg}$ of $\mathrm{FeCl}_{3} \cdot 6 \mathrm{H}_{2} \mathrm{O}$ and $5.9 \mathrm{mg}$ of $\mathrm{FeCl}_{2} \cdot 4 \mathrm{H}_{2} \mathrm{O}$ and adjusting the $\mathrm{pH}$ value at $10-11$ with a $25 \%$ aqueous ammonia solution by applying ultrasonic stirring for $30 \mathrm{~min}$ under nitrogen atmosphere. The resulting dispersion was maintained at $80^{\circ} \mathrm{C}$ under magnetic stirring and nitrogen atmosphere for $60 \mathrm{~min}$. Finally, once cold at room temperature, the resulting $m$-MWCNTs were washed with water up to neutral $\mathrm{pH}$ and dried at $37^{\circ} \mathrm{C}$.

\subsubsection{Preparation of $m-M W C N T s(-H R P)$-anti-HFA conjugates}

A dispersion was prepared with $1.5 \mathrm{mg}$ of $m$-MWCNTs in $2 \mathrm{~mL}$ of $100 \mathrm{mM}$ PBS of pH 7.0 with ultrasonic stirring for $30 \mathrm{~min}$. Next, $1 \mathrm{~mL}$ of a solution composed of $400 \mathrm{mM}$ EDC and $100 \mathrm{mM}$ NHSS in the same buffer was added and incubated in the dark with magnetic stirring for $6 \mathrm{~h}$. The resulting suspension was centrifuged at $14,000 \mathrm{rpm}$ and room temperature during $5 \mathrm{~min}$ and, thereafter, $1 \mathrm{~mL}$ of a solution containing $5 \mu \mathrm{g} / \mathrm{mL}$ of detection antibody (anti-HFA) and $1 \mathrm{mg} / \mathrm{mL}$ of HRP in $100 \mathrm{mM}$ PBS of pH 7.0 was added. After an incubation period of $24 \mathrm{~h}$ under magnetic stirring, the conjugates were washed three times with $10 \mathrm{mM}$ PBS of $\mathrm{pH} 7.0$, and the residue was re-dispersed in $1 \mathrm{~mL}$ of $100 \mathrm{mM}$ PBST of $\mathrm{pH} 7.0$.

\subsubsection{Preparation of anti-HFA-Biotin-Strept-Phe-SPCE immunosensor}

Grafted SPCEs (Procedure 2.3.1) were treated with $5 \mu \mathrm{L}$ of a $100 \mathrm{mM}$ each EDC/NHSS solution in $25 \mathrm{mM}$ MES buffer of $\mathrm{pH} 5.0$ and incubated for $30 \mathrm{~min}$. Then, the modified electrode was washed with water and let dry. Immobilization of Strept was performed by dropping $5 \mu \mathrm{L}$ of a $600 \mu \mathrm{g} / \mathrm{mL}$ solution in the same buffer and incubation for $60 \mathrm{~min}$. Once the Strept-Phe-SPCEs were washed with water and dried, the biotinylated capture antibody (Biotin-anti-HFA) was immobilized by depositing $5 \mu \mathrm{L}$ of a $7 \mu \mathrm{g} / \mathrm{mL}$ solution in $0.01 \mathrm{M}$ PBS of $\mathrm{pH} 7.4$ and incubated for $60 \mathrm{~min}$. A blocking step was implemented by adding $5 \mu \mathrm{L}$ of a $1.5 \mathrm{mg} /$ $\mathrm{mL}$ Biotin solution and incubation for $30 \mathrm{~min}$.

\subsubsection{Determination of HFA}

After a washing and drying step, $5 \mu \mathrm{L}$ of antigen solution (or the sample) were added and incubated for $60 \mathrm{~min}$ onto the resulting anti-HFA-Biotin-Strept-Phe-SPCE immunosensor. Thereafter, $5 \mu \mathrm{L}$ of the $m$-MWCNTs(-HRP)-anti-HFA conjugate were added and, after $60 \mathrm{~min}$, the bioelectrodes were washed with water and then stored until use by addition of a drop of $50 \mathrm{mM}$ phosphate buffer solution of $\mathrm{pH}$ 6.0. The determination of HFA was accomplished by dropping $45 \mu \mathrm{L}$ of a $1 \mathrm{mM}$ HQ solution prepared in $0.5 \mathrm{M}$ phosphate buffer solution of $\mathrm{pH} 6.0$ onto the surface of the horizontally postioned $m$-MWCNTs(-HRP)-anti-HFA-HFA-anti-HFA-Biotin-Strept-Phe-SPCE immunosensor and by applying a potential of $-200 \mathrm{mV}$. Once the background current was stabilized ( $100 \mathrm{~s}$ approximately), $5 \mu \mathrm{L}$ of a $50 \mathrm{mM}$ $\mathrm{H}_{2} \mathrm{O}_{2}$ solution prepared in the same buffer were added and allowed to incubate for $200 \mathrm{~s}$. Then, the current produced by the electrochemical reduction of benzoquinone was measured.

\subsubsection{Analysis of HFA in saliva}

Saliva samples were obtained from volunteers and collected using a Salivette ${ }^{\circledR}$ collection device (Sarstedt). Briefly, once rinsed the mouth thoroughly with water, a cotton swab was inserted into the mouth and chewed for $1 \mathrm{~min}$. Then, the swap saturated with saliva was inserted into the vial, sealed with the cap and centrifuged for $10 \mathrm{~min}$ at $3000 \mathrm{rpm}$. After this, $10-\mu \mathrm{L}$ sample aliquots were diluted with $990 \mu \mathrm{L}$ of 0.01 PBS of $\mathrm{pH}$ 7.4. The determination was performed immediately by applying the procedure described above to $5 \mu \mathrm{L}$ of diluted saliva, and interpolation of the amperometric response into the calibration plot constructed with standard solutions.

\section{Results and discussion}

As described in Procedure 2.3.2, m-MWCNTs were prepared by acidic oxidation of MWCNTs followed by incorporation of magnetic particles according with the method of Zhang et al. (2014) with slight modifications. Briefly, this procedure consisted of the treatment of carboxylated MWCNTs with $\mathrm{FeCl}_{3} \cdot 6 \mathrm{H}_{2} \mathrm{O}$ and $\mathrm{FeCl}_{2} \cdot 4 \mathrm{H}_{2} \mathrm{O}$ in ammonia solution at $80^{\circ} \mathrm{C}$ under nitrogen atmosphere. Thereafter (Fig. 1 inset), anti-HFA and HRP were covalently immobilized onto the prepared $m$-MWCNTs through EDC-NHSS chemistry (Akter et al., 2016). Fig. 1 also shows schematically the different steps involved in the preparation of the $m$-MWCNTs(-HRP)-anti-HFA-HFA-anti-HFA-Biotin-Strept-Phe-SPCE immunosensor. As it was described in the Experimental section, the SPCE surface was functionalized by grafting of $p$-ABA cation radical followed by covalent immobilization of streptavidin. The biotinylated capture antibody, anti-HFA-Biotin, was immobilized trough streptavidin-biotin interaction and a sandwich assay configuration was implemented with $m$-MWCNTs(-HRP)-anti-HFA.

The determination of HFA was accomplished by measuring the current produced by the electrochemical reduction of benzoquinone at $-200 \mathrm{mV}$ upon addition of $\mathrm{H}_{2} \mathrm{O}_{2}$ as HRP substrate.

Magnetic MWCNTs ( $m$-MWCNTs) were characterized by scanning electron microscopy (SEM), transmission electron microscopy (TEM), $\mathrm{X}$-Ray diffraction (XRD) and energy-dispersive X-Ray spectroscopy (EDS). As it can be seen in Fig. 2a and b, as well as in the photograph showing MWCNTs and $m$-MWCNTs upon applying an external magnet, $\mathrm{Fe}_{3} \mathrm{O}_{4}$ particles were attached to the walls of MWCNTs. X-Ray diffraction recordings of $m$-MWCNTs and MWCNTs are shown in Fig. 2c. It can be observed the peaks corresponding to the structure of MWCNTs (red response) also appearing in that of $m$-MWCNTs (blue response), together with other peaks that can be attributed to the different types of common iron oxides (Kim et al., 2010) (Gong et al., 2009). Peaks appearing at $2 \theta=30.2^{\circ} ; 35.7^{\circ} ; 43.3^{\circ}$ and $57.2^{\circ}$ can be assigned to magnetite $\left(\mathrm{Mn}, \mathrm{Fe}_{3} \mathrm{O}_{4}\right)$ or maghemite $\left(\mathrm{Mh}, \gamma-\mathrm{Fe}_{2} \mathrm{O}_{3}\right)$. Other peaks appearing at $2 \theta=53.9^{\circ}$ and $62.8^{\circ}$ can be related to the presence of the non-magnetic ( $\mathrm{Hm}, \alpha-\mathrm{Fe}_{2} \mathrm{O}_{3}$ ). Moreover, chemical analysis using EDS (Fig. 2d) demonstrated the presence of $\mathrm{Fe}, \mathrm{O}$ and $\mathrm{C}$ in the $m$-MWCNTs.

The room-temperature magnetization hysteresis loop of $m$-MWCNTs was obtained using a vibrating sample magnetometer and compared with those of HOOC-MWCNTs and pure $\mathrm{Fe}_{3} \mathrm{O}_{4}$ particles prepared under the same reaction conditions. The results shown in Fig. S2 (Supplementary material) demonstrated the superparamagnetic behavior of $m$-MWCNTs, with a saturation magnetization of $9.89 \mathrm{emu} / \mathrm{g}$, which, as expected, was significantly lower than that of $\mathrm{Fe}_{3} \mathrm{O}_{4}$ particles $(62.12 \mathrm{emu}$ / g) owing to the presence of carbon nanotubes.

\subsection{Optimization of the experimental variables}

The different variables affecting the preparation of $m$-MWCNTs(-HRP)-anti-HFA conjugate, anti-HFA-Biotin-Strept-Phe-SPCE, and the performance of the resulting $m$-MWCNTs(-HRP)-anti-HFA-HFA-anti-HFA-Biotin-Strept-Phe-SPCE immunosensor were evaluated and optimized. The largest ratio between the currents measured with the as prepared immunosensor in the presence (S), at a $250 \mathrm{pg} / \mathrm{mL}$ concentration level, or in the absence $(\mathrm{N})$ of the target compound was taken as the selection criterion for each tested variable. The optimization studies involved evaluation of: a) loadings of HRP and anti-HFA onto m-MWCNTs; b) loading of streptavidin covalently linked to $p$-ABA-modified SPCE; c) anti-HFA-Biotin loading onto Strept-Phe-SPCE; d) concentration of blocking agent. The results of these tests are discussed in the 


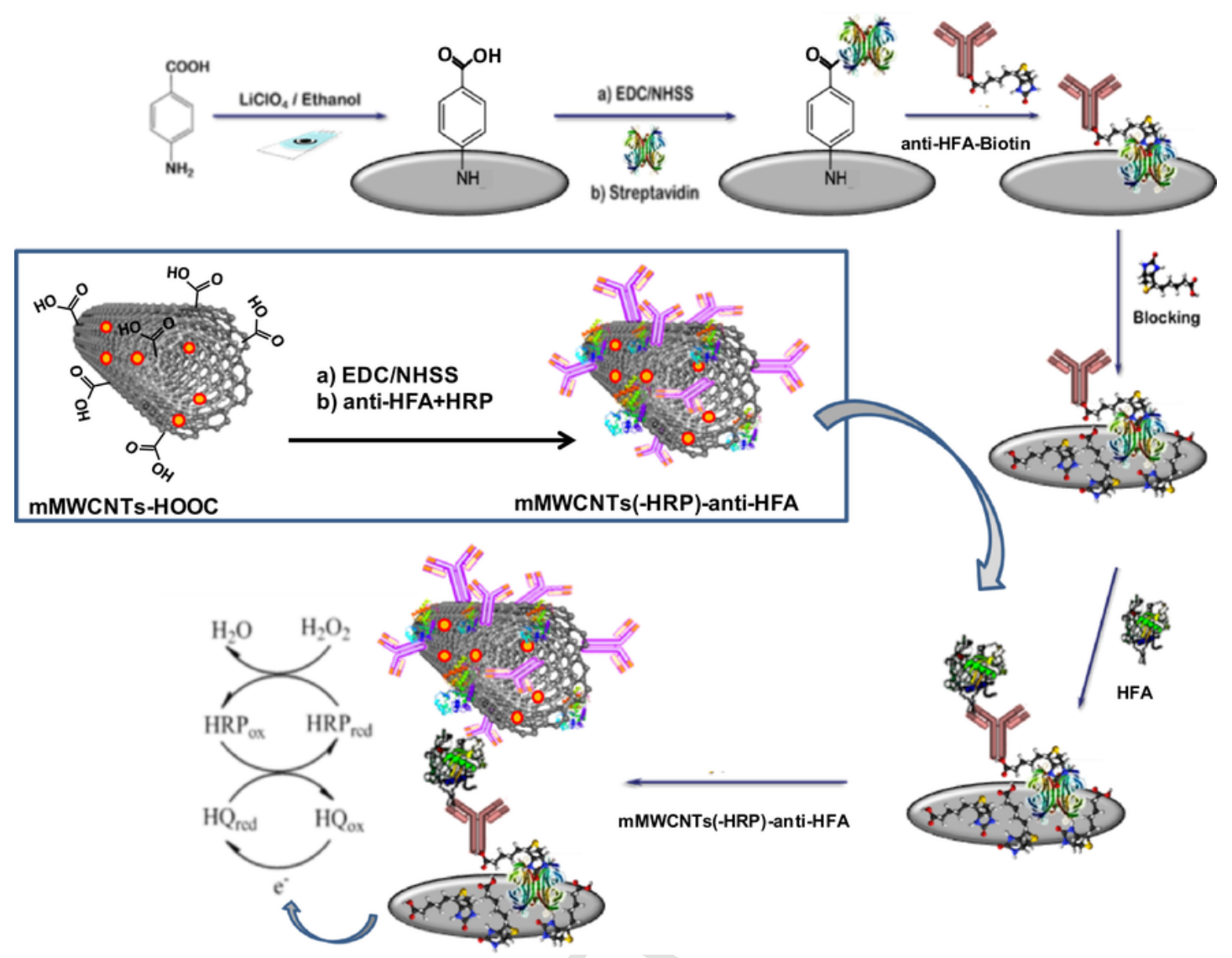

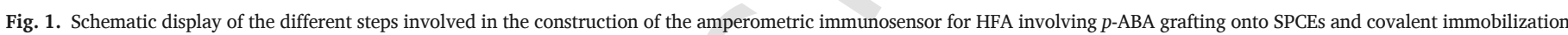
of Strept followed by Biotin-anti-HFA conjugation and sandwich assay with $m$-MWCNTs(-HRP)-anti-HFA.

Supplementary material (Figs. S2-S4). Moreover, the experimental conditions used for SPCE modification by grafting from the electrochemically generated $p$-ABA cation radical and covalent bond of streptavidin were optimized previously (Ojeda et al., 2012). Similarly, the detection potential of $-200 \mathrm{mV}$ was also previously selected for the same catalytic system (Eguílaz et al., 2010).

All the steps involved in the immunosensor preparation were monitored by electrochemical impedance spectroscopy and cyclic voltammetry using $2 \mathrm{mM} \mathrm{Fe}(\mathrm{CN})_{6}{ }^{4-/ 3-}$ as the redox probe in $0.1 \mathrm{M}$ phosphate buffer solution of $\mathrm{pH}$ 7.4. Fig. 3a shows as modification of the SPCE with p-ABA gave rise to a large increase in the electron transfer resistance, $\mathrm{R}_{\mathrm{CT}}$, varying from 376 to $1885 \Omega$ as a consequence of the electrostatic repulsion between the redox probe and the negatively charged carboxylate groups. After activation with EDC/NHSS and immobilization of streptavidin, the $R_{C T}$ value dramatically decreased $\left(R_{C T}=957 \Omega\right)$, while showed a further increase after conjugation with anti-HFA-Biotin $\left(\mathrm{R}_{\mathrm{CT}}=1513 \Omega\right)$ due to the partially insulating barrier on the electrode surface produced by the presence of proteins. The blocking of the remaining unreacted sites with biotin produced a larger $R_{C T}$ value of $1711 \Omega$ in agreement with the expected decrease in the electrode conductivity at a quasi-passivated surface. Surprisingly, further conjugation of HFA antigen provoked a decrease in the charge transfer resistance, $\mathrm{R}_{\mathrm{CT}}=1497 \Omega$. A possible explanation of this behavior relies with incorporation of biotin, which is dissociated at the working $\mathrm{pH}$ value, and provokes a high increase in $\mathrm{R}_{\mathrm{CT}}$ due to charge repulsion. The subsequent incorporation of the antigen led the charge transfer resistance to values similar that measured before the blocking step. In addition, lower $\mathrm{R}_{\mathrm{CT}}(1184 \Omega)$ was observed for the $m$-MWCNTs(-HRP)-anti-HFA-HFA-anti-HFA-Biotin-Strept-Phe-SPCE immunosensor probably a consequence of the high conductivity inherent to the modified carbon nanotubes.

Similar changes and conclusions were apparent from CV especially in the early stages of immunosensor preparation. The voltammogram corresponding to the bare SPCE (curve 1) shows the characteristic oxidation and reduction peaks of the redox pair at potential values of +0.27 and $-0.06 \mathrm{~V}$, respectively, while the anodic and cathodic currents exhibited approximately the same magnitude $(130 \mu \mathrm{A})$. Modification of SPCE by grafting with p-ABA (curve 2) caused a decrease in the peak currents and a larger separation of peak potentials which is most likely due to the electrostatic repulsion between the redox probe and the dissociated carboxyl groups on the electrode surface. When streptavidin is linked (curve 3), the corresponding voltammogram shows a behavior more similar that of the unmodified electrode, probably due to the lower effect of charge repulsion. Successive incorporation of the other immunoreagents provoked slight variations in the CVs towards a less reversible behavior, as a consequence of the presence of insulating layers of increasing thickness on the electrode surface.

\subsection{Analytical characteristics for HFA determination}

Under the optimized working conditions, a calibration plot for HFA (Fig. 4) was constructed over the $10-5000 \mathrm{pg} / \mathrm{mL}$ concentration range. A linear range between 20 and $2000 \mathrm{pg} / \mathrm{mL}$ was found $\left(\mathrm{r}^{2}=0.995\right)$ which fitted to the equation: $\mathrm{i}, \mu \mathrm{A}=2.17 \pm 0.07 \log [\mathrm{HFA}, \mathrm{pg} / \mathrm{mL}$ ] $-2.22 \pm 0.4$. A mandatory comparison is the calibration plot constructed using MWCNTs(-HRP)-anti-HFA as the carrier tag, i.e., without magnetic particles incorporated to the nanotubes. In this latter case, a calibration graph with a lower slope value $(1.21 \pm 0.05 \mu \mathrm{A}$ per decade of 
a)

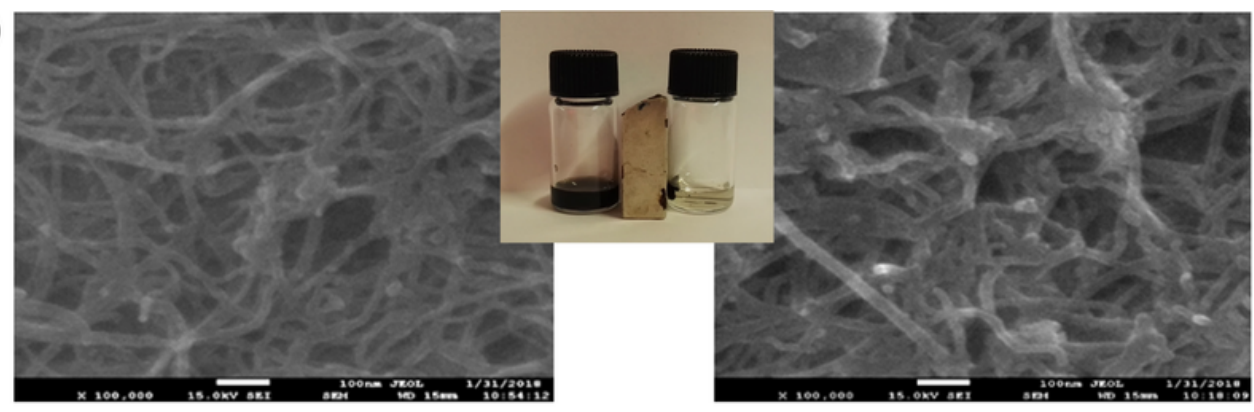

b)
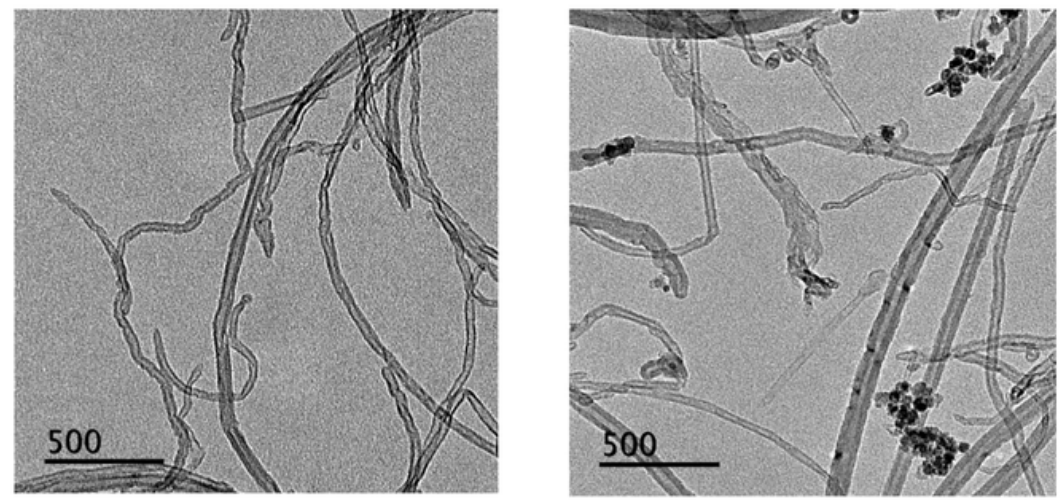

d)
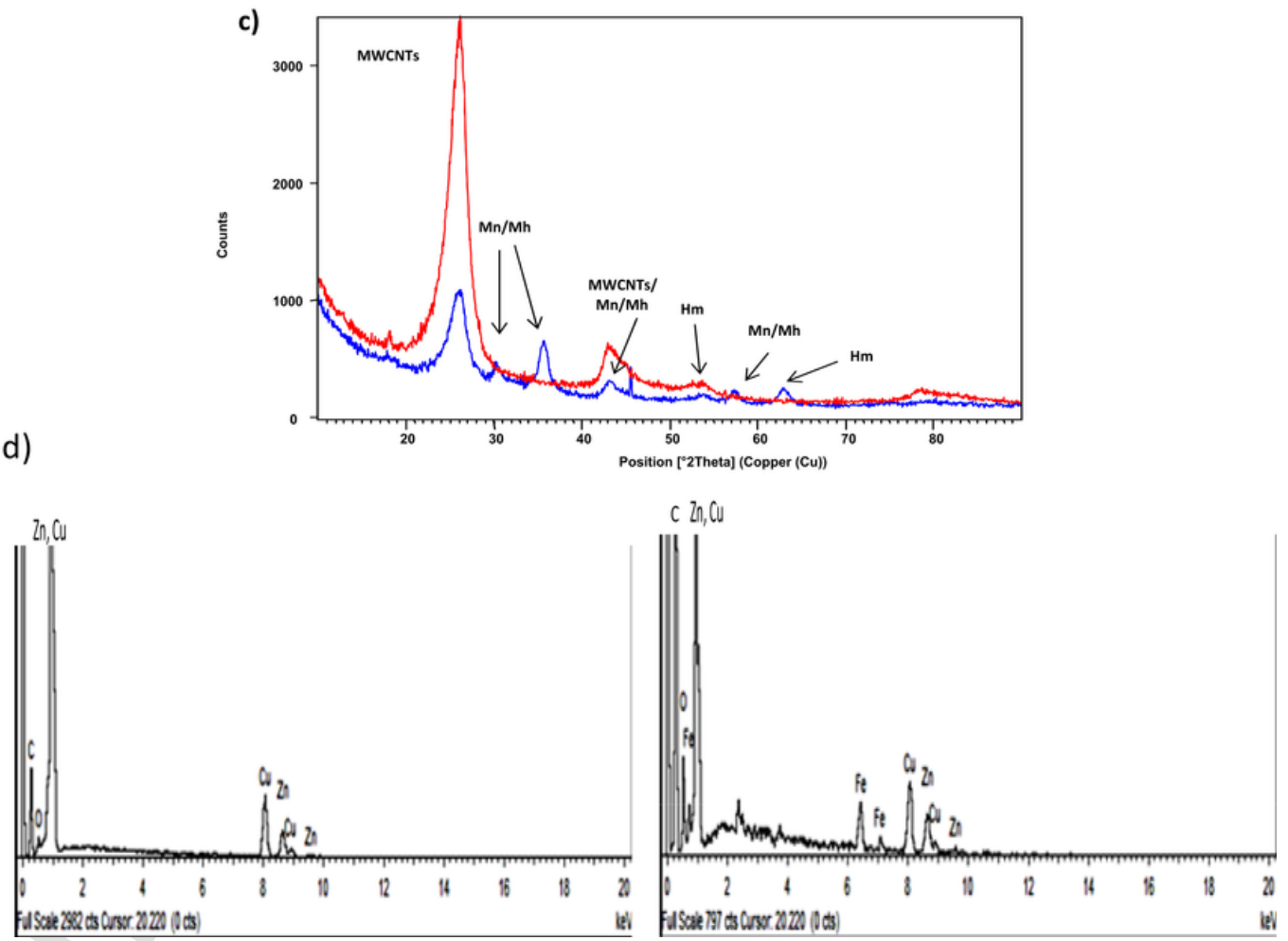

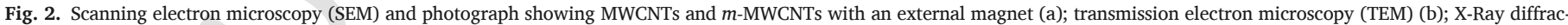

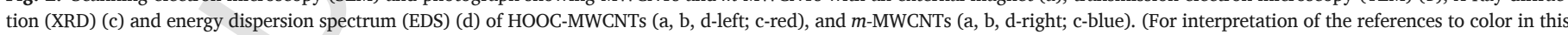
figure legend, the reader is referred to the web version of this article.).

concentration) was obtained over the same dynamic range $\left(r^{2}=0.997\right)$. The higher sensitivity achieved with the magnetic nanoparticles highlights their favorable contribution to enhance conductivity and ability of carbon nanotubes for biomolecules adsorption. According with Zhang et al. (2014), m-MWCNTs used as labels of anti-HFA secondary antibodies offer a large specific surface area and promote electron transfer between the solution and the electrode. The improved analytical performance can also be partially attributable to the magnetic 

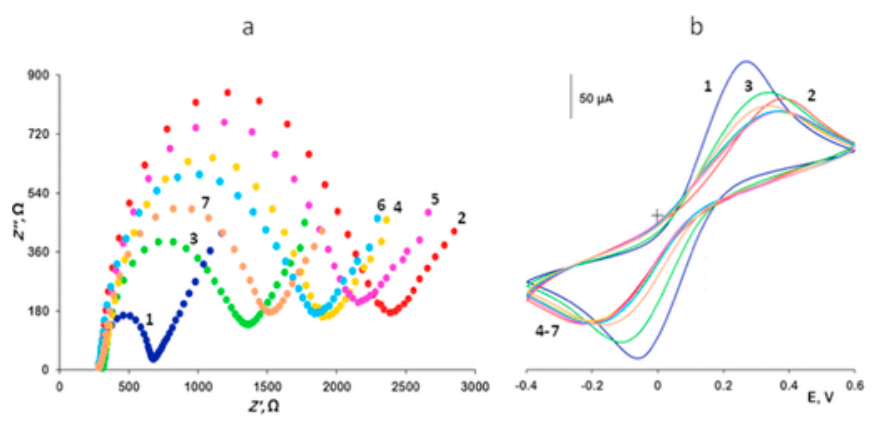

Fig. 3. Nyquist plots (a) and cyclic voltammograms (b) recorded in a $2 \mathrm{mM} \mathrm{Fe}(\mathrm{CN})_{6}$ $3-/ 4-0.1 \mathrm{M}$ phosphate buffer solution of $\mathrm{pH} 7.4$ for bare SPCE (1); p-ABA-SPCE (2); Strept-Phe-SPCE (3); anti-HFA-Biotin-Strept-Phe-SPCE (4); blocking with Biotin (5); HFA-anti-HFA-Biotin-Strept-Phe-SPCE (6); $m$-MWCNTs(-HRP)-anti-HFA-HFA-anti-HFA-Biotin-Strept-Phe-SPCE (7); $250 \mathrm{pg} / \mathrm{mL}$ HFA; range of frequencies, $10^{5}-0.040 \mathrm{~Hz}$; open circuit (a); $50 \mathrm{mV} / \mathrm{s}$ (b).

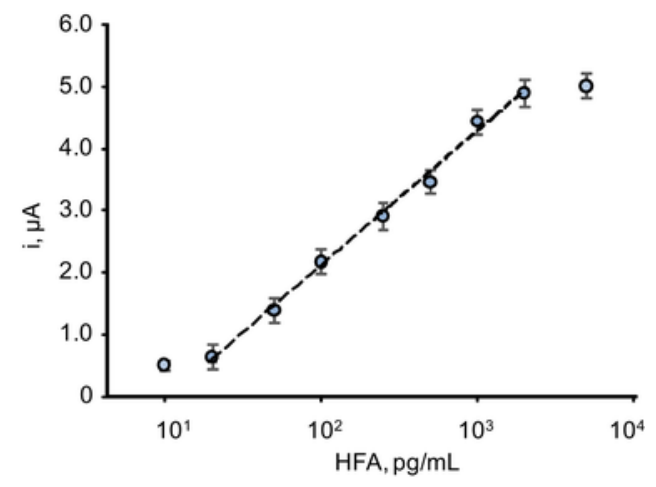

Fig. 4. Calibration plot for HFA constructed with the mMWCNTs(-HRP)-anti-HFA-HFA-anti-HFA-Biotin-Strept-Phe-SPCE immunosensor.

particles weak pseudo-peroxidase activity. Nevertheless, the enzymatic catalysis by HRP of the hydrogen peroxide reaction is much more important, as it can be deduced from the much smaller slope value, $\mathrm{m}=0.102 \pm 0.02 \mu \mathrm{A}$ per decade of concentration, of the calibration graph in the same range of HFA concentrations constructed with the immunosensor using $m$-MWCNTs-anti-HFA label without HRP enzyme. This biosensor showed also a poorer linearity $\left(r^{2}=0.95\right)$. To highlight the relevant effect for signal amplification provided by the use of $m$-MWCNTs(-HRP)-anti-HFA label, the results obtained with the as prepared $m$-MWCNTs(-HRP)-anti-HFA-HFA immunosensor were compared with those achieved with a HRP-IgG-anti-HFA-HFA-anti-HFA-Biotin-Strept-Phe-SPCE immunosensor. Fig. S5 in Supplementary material shows as the current measured for $250 \mathrm{pg} / \mathrm{mL}$ HFA was approximately three times larger using $m$-MWCNTs(-HRP)-anti-HFA conjugate as the carrier tag. Moreover, despite the higher current achieved for HFA detection, the unspecific signals represented only less than 13 per cent of such magnitude, thus providing a high $\mathrm{S} / \mathrm{N}$ ratio.

The linear range of the calibration plot $(20-2000 \mathrm{pg} / \mathrm{mL})$ covers much lower HFA concentrations and in a wider interval than those claimed for the ELISA kit (https://www.rndsystems.com/products/ human-fetuin-a-quantikine-elisa-kit_dfta00), $7.8-500 \mathrm{ng} / \mathrm{mL} \mathrm{HFA,} \mathrm{as}$ well as the comparison is made against the electrochemical immunosensor reported by Silva et al. (2016), $0.5-25 \mu \mathrm{g} / \mathrm{mL}$. The limit of detection achieved with our immunosensor design was calculated according with the $3 \mathrm{~s}_{\mathrm{b}} / \mathrm{m}$ criterion, where $\mathrm{s}_{\mathrm{b}}$ was estimated as the standard deviation, expressed in concentration units, for 10 blank current measurements $(0 \mathrm{pg} / \mathrm{mL} \mathrm{HFA})$. The obtained LOD value, $16 \mathrm{pg} / \mathrm{mL}$, is notably better (more than $10^{3}$ times lower) than that reported in (Silva et al., 2016), $0.017 \mu \mathrm{g} / \mathrm{mL}$, and the minimum detectable dose (MDD) of the ELISA kit, $0.62 \mathrm{ng} / \mathrm{mL}$.
The reproducibility of the measurements performed with the developed immunosensor was evaluated. Amperometric measurements for 0 and $250 \mathrm{pg} / \mathrm{mL}$ HFA were made with five different immunosensors prepared simultaneously for each HFA concentration. The calculated RSD values were $6.7 \%$ and $7.4 \%$, respectively. Moreover, measurements were also carried out with five immunosensors prepared in five different days. In this case, the RSD values were $7.2 \%$ and $7.5 \%$ for the same concentration levels, respectively. On the other hand, the storage stability of anti-HFA-Biotin-Strept-Phe-SPCEs was evaluated by preparing the same day various immunosensors which were used for measuring the amperometric responses of $250 \mathrm{pg} / \mathrm{mL} \mathrm{HFA}$ in different days, once the blocking reagent and the $m$-MWCNTs(-HRP)-anti-HFA conjugate were added. Between measurements, the bioelectrodes were stored at $-20^{\circ} \mathrm{C}$ in dry ambient. The results obtained (Fig. S6a) revealed that the initial immunosensor response was maintained within the limits of control set by \pm 3 times the standard deviation of the measurements $(n=3)$ carried out on the first day, during 40 days after the immunosensor preparation thus showing an excellent storage stability.

In addition, the stability of the $m$-MWCNTs(-HRP)-anti-HFA conjugates was also checked by preparing an amount of them and keeping in the refrigerator at $4{ }^{\circ} \mathrm{C}$. A new immunosensor was prepared each working day with a different conjugate and used to measure the current corresponding to $250 \mathrm{pg} / \mathrm{mL}$ HFA. The results shown in Fig. S6b confirmed a storage stability of the conjugates for at least 30 days after their preparation.

\subsection{Selectivity}

Various proteins (bovine serum albumin (BSA), interleukin 1 beta (IL-1ß), interleukin 6 (IL-6), interleukin 8 (IL-8), human immunoglobulin $\mathrm{G}(\mathrm{IgG})$, tumor necrosis factor alpha $(\mathrm{TNF}-\alpha)$, and transforming growth factor beta 1 (TGF- $\beta 1$ )), as well as other compounds potentially present in samples containing HFA, such as creatinine (CR), ascorbic acid (AA), uric acid (UA), cortisol (CL), and estradiol (E2) were tested as potential interfering substances for the determination of HFA with the developed immunosensor. The evaluation of the selectivity was accomplished by comparing the immunosensor responses for 0 and $250 \mathrm{pg} / \mathrm{mL}$ HFA in the absence and in the presence of each tested compound at a concentration corresponding approximately to the normal level in the undiluted saliva samples, except BSA, which was tested at a higher concentration. Fig. 5 shows that not significantly different currents were measured in all cases with the current mean values within the $\pm 2 \times$ standard deviation range of the current measured in the absence of interferent.

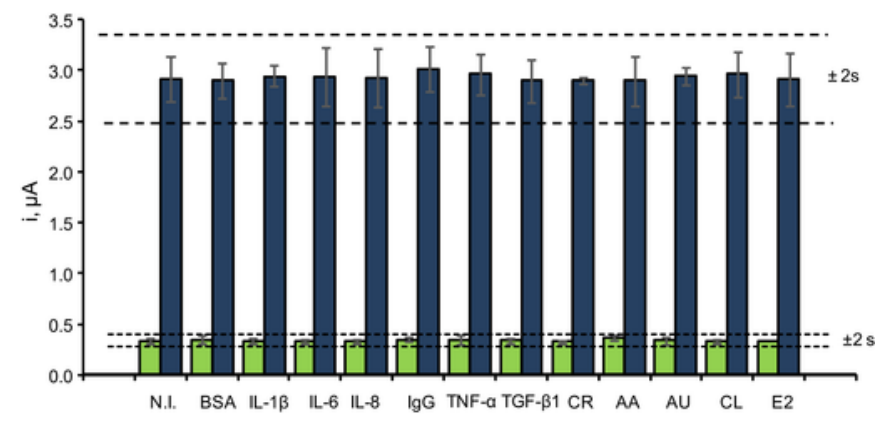

Fig. 5. Effect of the presence of $5 \mathrm{mg} / \mathrm{mL}$ bovine serum albumin (BSA), $50 \mathrm{pg} / \mathrm{mL}$ interleukin 1 beta (IL-1 $\beta$ ), $50 \mathrm{pg} / \mathrm{mL}$ interleukin 6 (IL-6), $250 \mathrm{pg} / \mathrm{mL}$ interleukin 8 (IL-8), $16 \mu \mathrm{g} / \mathrm{mL}$ human immunoglobulin $\mathrm{G}$ (IgG), $200 \mathrm{pg} / \mathrm{mL}$ tumor necrosis factor alfa (TNF- $\alpha$ ), $500 \mathrm{pg} / \mathrm{mL}$ transforming growth factor beta 1 (TGF- $\beta 1$ ), $10 \mathrm{pg} / \mathrm{mL}$ creatinine (CR), $370 \mu \mathrm{g} / \mathrm{mL}$ ascorbic acid (AA), $50 \mu \mathrm{g} / \mathrm{mL}$ uric acid (UA), $12 \mathrm{ng} / \mathrm{mL}$ cortisol (CL), and $200 \mathrm{pg} / \mathrm{mL}$ estradiol (E2) on the amperometric responses obtained for $0(\square)$ or $250(\square)$ $\mathrm{pg} / \mathrm{mL}$ HFA at the mMWCNTs(-HRP)-anti-HFA-HFA-anti-HFA-Biotin-Strept-Phe-SPCE immunosensor. 


\subsection{Determination of HFA in saliva}

The usefulness of the immunosensor in the analysis of real samples was tested by analyzing saliva from two smoker and non-smoker-volunteers. This type of sample was chosen because, as indicated in the Introduction section, HFA plays an important role in the detection of dental inflammatory processes (Doğan al, 2016). In addition, saliva is increasingly recognized as an attractive fluid for diagnostics since it allows a non-invasive cost-efficient sample collection method among other advantages (Campuzano et al., 2017). With the aim of minimizing the possible matrix effects and to fit the HFA concentration in the samples within the obtained range of linearity, various saliva dilution factors using 0.01 M PBS of pH 7.4 were assayed. As it is shown below, these requirements were achieved by applying a 100 -fold dilution to the sample.

Under these conditions, the possible existence of matrix effects was tested by comparing the slope value of the calibration plots constructed by successive addition of HFA standard aliquots to the diluted samples, with the slope of the calibration graph prepared with buffered HFA standard solutions (Fig. 4). Slope values of $2.16 \pm 0.03$ and $2.17 \pm 0.03$ $\mu \mathrm{A}$ per decade of concentration were found in non-smoker and smoker saliva, respectively, which were very similar to that of the calibration graph constructed with HFA standards, $2.17 \pm 0.07 \mu$ A per decade of concentration. The application of the Student $t$-test provided $t_{\exp }$ values much lower than the tabulated one, $\mathrm{t}_{\mathrm{tab}}=2.262$ for $\alpha=0.05$ and $\mathrm{n}=9$. Therefore, the determination of HFA in saliva could be performed directly by interpolation of the amperometric current measured with the immunosensor for an aliquot of the 100 -fold diluted sample into the calibration plot constructed with standard solutions. Fig. S7 (Supplementary Material) displays the calibration plot obtained with the saliva samples overlapped with that constructed from standard HFA solutions in PB buffer showing the coincidence between them.

The concentrations found in the analysis of the saliva samples were $44.6 \pm 0.5$ and $43.0 \pm 0.2 \mathrm{ng} / \mathrm{mL}$ for the smoker and non-smoker individuals $(n=5)$ showing, as expected, that no important differences are apparent in the absence of inflammatory disease. These results were compared with those obtained using the commercial ELISA kit, $44.8 \pm 0.8 \mathrm{ng} / \mathrm{mL}$ and $42.9 \pm 0.6 \mathrm{ng} / \mathrm{mL}(\mathrm{n}=4)$, respectively. As it is obvious, an excellent agreement between the results obtained by both methods was apparent, what is also in agreement with that reported in the literature for saliva of healthy individuals, $41 \mathrm{ng} / \mathrm{mL}$ (Doğan al, 2016). All these results demonstrated the usefulness of the developed immunosensor for the analysis of HFA at low concentration levels in saliva with minimal sample treatment.

\section{Conclusions}

This paper reports the first amperometric immunosensor for the determination of the biomarker HFA. The designed strategy involved SPCEs grafted with $p$-aminobezoic acid for covalent binding of streptavidin, and a sandwich configuration with biotinylated capture antibody and magnetic MWCNTs conjugated with HRP and anti-HFA antibodies as the detection label. The use of this signal amplification approach provides important analytical advantages in terms of wider linear dynamic concentration range and sensitivity with respect to commercial ELISA kits as well as to the only electrochemical immunosensor (chronoimpedimetric) reported so far for HFA. Importantly, the developed immunosensor can be used to determine HFA in saliva with minimal sample treatment. Other relevant advantages of the developed immunosensor are the great reproducibility of the measurements, both with immunosensors prepared on the same day and on different days, and the excellent storage stability and selectivity. This immunosensing strategy can be easily extended to the electrochemical determination of other biomarkers since the disposable electrode surface modification protocol and the use of magnetic multiwalled carbon nanotubes as nanocarrier tags can be viewed as general working approaches to design other electrochemical immunoplatforms.

\section{Acknowledgement}

The financial support of projects CTQ2015-70023-R (Spanish Ministry of Economy and Competitivity Research Projects), and S2013/ MT-3029 (NANOAVANSENS Program from the Comunidad de Madrid) are gratefully acknowledged.

\section{Appendix A. Supporting information}

Supplementary data associated with this article can be found in the online version at doi:10.1016/j.bios.2018.04.056.

\section{References}

Akter, R., Jeong, B., Choi, J.-S., Rahman, Md.A., 2016. Biosens. Bioelectron. 80, 123-130. Bertok, T., Sediva, A., Katrlik, J., Gemeiner, P., Mikula, M., Nosko, M., Tkac, J., 2013. Talanta 108, 11-18.

Bertok, T., Gemeiner, P., Mikula, M., Gemeiner, P., Tkat, J., 2013. Microchim. Acta 180, 151-159.

Campuzano, S., Yáñez-Sedeño, P., Pingarrón, J.M., 2017. TrAC Trends Anal. Chem. 86 14-24.

Choi, K.M., 2016. Endocrinol. Metab. 31, 1-6.

Dabrowska, A.M., Taracha, J.S. Wojtysiak-Duma, B., Dumac, D. 2015. Biomedical Papers of the Medical Faculty of the University Palacky, Olomouc, Czech Republic, 159, pp. 352-359.

Ding, L., Bond, A.M., Zhai, J., Zhang, J., 2013. Anal. Chim. Acta 797, 1-12.

Doğan, G.E., Demír, T., Laloğlu, E., Sağlam, E., Aksoy, H., Yildirim, A., Akçay, F., 2016. Braz. Oral. Res. 30, e129.

Dziegielewska, K.M., Brown, W.M., Casey, S.-J., Christie, D.L., Foreman, R.C., Hill, R.M., Saunders, N.R., 1990. J. Biol. Chem. 265, 4354-4357.

Eguílaz, M., Moreno-Guzmán, M., Campuzano, S., González-Cortés, A., Yáñez-Sedeño, P., Pingarrón, J.M., 2010. Biosens. Bioelectron. 26, 517-522.

Gong, J.-L., Wang, B., Zeng, G.-M., Yang, C.P., Niu, C.-G., Niu, Q.-Y., Zhou, Y., Liang, W.-J., 2009. J. Hazard. Mater. 164, 1517-1522.

Kim, I.T., Nunnery, G.A., Jacob, K., Schwartz, J., Liu, X., Tannenbaum, R., 2010. J. Phys. Chem. 114, 6944-6951.

Nagaraj, V.J., Aithal, S., Eaton, S., Bothara, M., Wiktor, P., 2010. Nanomedicine 5, 369-378.

Ojeda, I., López-Montero, J., Moreno-Guzmán, M., Janegitz, B.C., González-Cortés, A., Yáñez-Sedeño, P., Pingarrón, J.M., 2012. Anal. Chim. Acta 743, 117-124.

Sakwe, A.M., Koumangoye, R., Goodwin, S.J., Ochieng, J., 2010. J. Biol. Chem. 285, 41827-41835.

Schinke, T., Amendt, C., Trindl, A., Pöschke, O., Müller-Esterl, W., Jahnen-Dechent, W., 1996. J. Biol. Chem. 23, 20789-20796.

Silva, P.M.S., Lima, A.L.R., Silva, B.V.M., Coelho, L.C.B.B., Dutra, R.F., Correia, M.T.S., 2016. Biosens. Bioelectron. 85, 171-177.

Uygun, Z.O., Şahin, , Yılmaz, M., Akçay, Y., Akdemir, A., Sağın, F., 2018. Anal. Biochem. $542,11-15$.

Yáñez-Sedeño, P., Campuzano, S., Pingarrón, J.M., 2017. J. Carbon Res. 2017 (3), 3. https: //doi.org/10.3390/ c3010003.

Yi, J.K., Chang, J.W., Han, W., Lee, J.W., Ko, E., Kim, D.H., Bae, J., Yu, J., Lee, C., Yu, M., Noh, D., 2009. Cancer Epidemiol. Biomark. Prev. 18, 1357-1364.

Yilmaz, Y., Yonal, O., Kurt, R., Ari, F., Oral, A.Y., Celikel, C.A., Korkmaz, S., Ulukaya, E., Ozdogan, O., Imeryuz, N., Avsar, E., Kalayci, C., 2010. Ann. Clin. Biochem. 47, 549-553.

Zhang, Q., Chen, X., Tu, F., Yao, C., 2014. Biosens. Bioelectron. 59, 377-383. 